\title{
Peritoneal Dialysis in Europe: An Analysis of Its Rise and Fall
}

\author{
Norbert Lameire Patrick Peeters Raymond Vanholder Wim Van Biesen \\ Renal Division, University Hospital Ghent, Ghent, Belgium
}

\section{Key Words}

Renal replacement therapy • End-stage renal disease • Peritoneal dialysis

\begin{abstract}
There is a wide variability in the utilization of peritoneal dialysis throughout Europe that cannot be explained by differences in medical factors alone. Over the last years, the utilization of peritoneal dialysis has even changed in individual countries. The main factors of this variation are not medical, but rather changes in reimbursement and other financial considerations. The overall structure of the health care in an individual country is to a large extent determining the use of a renal replacement therapy modality.
\end{abstract}

Copyright (C) 2006 S. Karger AG, Basel

\section{Introduction}

Peritoneal dialysis (PD) was introduced as a homebased renal replacement therapy (RRT) in 1978 when Oreopoulos et al. [1] first described continuous ambulatory PD (CAPD) using plastic bags. The simplicity of the therapy (four 2-liter exchanges per day) and its self-care, home-based nature made it very attractive. It was quickly and widely applied. By the mid to late 1980s, PD utilization rates were $>35 \%$ in Canada and $15 \%$ in the United States. Other countries, including the United Kingdom, Hong Kong, and Mexico, had much higher PD utilization rates, and worldwide, the growth rate of $\mathrm{PD}$ outstripped that of hemodialysis (HD). Already the first years after its introduction, wide differences in utilization of PD as dialysis modality became apparent. Some countries, including Japan, Germany, Belgium, and France, never had more than $10 \%$ of prevalent dialysis patients on PD. Over the last years, particularly in the US, Cana$\mathrm{da}$, and in some European countries, an even further decline was observed [2]. The reasons why these wide differences between countries have persisted, and why, at least in some countries, the already low prevalence of PD patients is further declining are probably to a certain extent the same.

In contrast with this negative evolution in the application of PD, there is no lack of European scientific interest in PD. Like on other continents, a high number of research groups have scientifically contributed to a better understanding of the physiology of PD, the investigation of the long-term structural and functional alterations of the membrane, the analysis of the long-term outcome of PD patients, and the improvement of the PD solutions and technology.

This paper will attempt to briefly analyze the different medical and non-medical factors involved in the initial and long-term utilization of PD in Europe.

\section{Medical Factors in the Selection of PD as RRT Modality}

Quite early after its introduction, a number of critical scientific remarks were formulated on PD as chronic dialysis modality with emphasis on the high dropout from

\section{KARGER}

Fax +4161306 1234

E-Mail karger@karger.ch

www.karger.com
(C) 2006 S. Karger AG, Basel

0253-5068/06/0241-0107\$23.50/0

Accessible online at:

www.karger.com/bpu
Norbert Lameire

Renal Division, University Hospital Ghent

185, De Pintelaan

BE-9000 Ghent (Belgium)

Tel. +32 9240 4524, Fax +329240 4599, E-Mail norbert.lameire@ugent.be 
the PD program due to peritonitis, catheter problems, and inadequate dialysis $[3,4]$. Technique failure rates for $\mathrm{PD}$ at $7-11 \%$ per year were generally higher than for HD, either due to patient 'burn-out' (reduced motivation due to increasing morbidity), recurrent peritonitis, or peritoneal membrane failure.

In the mid 1990s, articles reporting poor outcomes for PD patients, based on a data analysis of the US Renal Data System, were also a very important contributing factor to the reluctance to promote $\mathrm{PD}$, at least in some countries $[5,6]$.

However, improvements in connector technology and training techniques over the last decade have reduced peritonitis frequency, such that episodes per patient of less than 1 per 24 months are now the norm [7]. The introduction of more biocompatible PD solutions that are low in glucose degradation products has further reduced dialysis discomfort and promises additional reduction in peritonitis frequency and better long-term preservation of peritoneal structure and function. At least one recent study has shown improved patient survival with these new solutions, compared with the conventional fluids [8].

Furthermore, studies with better adjustment for comorbidities have found either no mortality differences or better survival with PD, especially in the first 2 years after starting dialysis [9-12]. However, survival differences between HD and PD are not constant, but vary substantially according to the underlying cause of end-stage renal disease (ESRD), age, and level of baseline comorbidity [13].

Very recent results of the Choices for Healthy Outcomes in Caring for ESRD study also suggest that the risk of death does not differ between patients undergoing PD and those undergoing HD during the first year of dialysis and that the risk of death with PD is not uniformly distributed among patients with ESRD. In patients with ESRD who had a better case-mix profile and the highest propensity for initially receiving PD, survival did not differ by dialysis type [14].

Additional medical concerns on PD were related to the achievement of sufficient dialysis, mainly based on small solute removal targets and on adequate peritoneal ultrafiltration, particularly in anuric patients [15]. Indeed, the Canada-USA (CANUSA) trial indicated that the targets for PD adequacy were higher than most patients were able to achieve with simple prescriptions [16]. Attempts to achieve these targets usually meant more exchanges, higher dialysate volumes, more adequacy assessments, and potentially higher costs. The simplicity of the thera- py, which was part of its appeal, and therefore sometimes therapy compliance were lost, and at least in some units, patients were prematurely transferred to HD in spite of doing clinically well [Van Biesen, pers. commun.].

Reanalysis of the CANUSA data [17] showed the importance of residual renal function as contributor to the small solute clearance, and the favorable outcome of also anuric PD patients [18] made nephrologists realize that the targets as derived from the CANUSA study might not be correct. It was the Adequacy of Peritoneal Dialysis in Mexico study that convincingly provided reasons for reconsidering and lowering the targets [19]. The intervention group received a dialysis dose that brought their total $\mathrm{Kt} / \mathrm{V}$ above 2.2, and the control arm had a total $\mathrm{Kt} / \mathrm{V}$ of approximately 1.8; the peritoneal components of the $\mathrm{Kt} / \mathrm{V}$ were 2.13 and 1.62 , respectively. The results showed no difference in 2-year mortality rates between the two groups overall and not in the subgroup analyses based on age, serum albumin, diabetes, or residual renal function. Although there remain concerns about the generalizability of these results, when compared with other studies on adequacy in PD, it is likely that dosing targets had to be reevaluated and lowered. This study also demonstrated that one can feel comfortable to maintain a patient on PD even when he/she is not achieving small solute targets, is feeling well, and is adequately nourished [20].

It was later recognized that high transporters, despite achieving conventional small solute dialysis targets, were characterized by ultrafiltration failure, hypertension, excess peritoneal loss of albumin, and excess mortality [2123]. However, the widespread introduction of automated PD, whereby dialysis fluid is exchanged frequently while the patient is asleep, improves ultrafiltration and even further reduces the time that the patient needs to devote to dialysis procedures, since in general, one extra daytime exchange is needed. Most patients, even those who are anuric, are suited to automated PD [24], but attention must be paid to the in general lower absolute sodium removal that is achieved in cycler PD [25]. However, the introduction of icodextrin dialysis fluid, containing a polyglucose that maintains a long-term osmotic pressure gradient, has reduced the problem of negative ultrafiltration during the night exchange or long day exchanges [26].

Hence, some of the medical concerns that were formulated in the early years of PD were appropriate, but over the last 10 years, most of them have been countered by improvements in the understanding of PD physiology and progress in technology. In the meantime, these concerns were partly responsible or at least used as arguments 
in some European countries, for reluctance to start PD and for unnecessary technique failure where PD was applied.

\section{Non-Medical Factors in the Selection of PD as RRT Modality}

Thus, medical factors alone cannot explain why the wide differences in PD utilization are still present, particularly in Europe, and why PD is even declining in some European countries.

It is clear that beyond medical and scientific factors, equally important non-medical factors must be involved in the wide variety in utilization of PD in some areas of the world and maybe also in the further decline over the last years [27]. Overall, according to Nissenson et al. [27, 28], these factors include lack of pre-ESRD patient education, late patient referral, limited presentation of dialysis modality choice to the patient, and a poor infrastructure of PD training, research, and physician experience in many renal replacement programs [29-31]. The problem is further complicated by evidence suggesting a physician bias toward HD [28]. This is the more surprising in view of recent findings indicating that $P D$ is an acceptable modality and has a high degree of patient satisfaction [32]. All these considerations suggest that nephrologists and primary care physicians should give greater attention to PD when patients are eligible for either modality, especially in light of no clear superiority of one modality over the other in patient survival.

The importance of patient education in the overall preESRD processes was recently corroborated by Mehrotra et al. [33] using data on incident ESRD patients admitted to 229 dialysis units in the ESRD Network in the USA. The majority of ESRD patients were not exposed to chronic PD, home HD, or renal transplantation as options $(66,88$, and $74 \%$, respectively). Using multivariate analysis, variables significantly associated with selection of chronic PD as modality were the fact that chronic PD was presented as a treatment option and the time spent on patient education. It appears thus that an incomplete presentation of treatment options is an important reason for under-utilization of home dialysis therapies, notably $\mathrm{PD}$, and probably also delays access to transplantation.

In some units in Belgium, many patients progressing towards ESRD are offered a structured predialysis education program. The goals of the program, based on both individualized information session(s) given to the patient and family by an experienced nurse, sometimes together with a psychologist and social worker, are to inform on all modalities of RRT, in order to decrease anxiety and promote self-care RRT modalities. In one such program, a high percentage of patients exposed to a structured predialysis education program started with a self-care RRT modality, including PD [34].

However, we believe that above all, financial and reimbursement issues are the most important non-medical determinants of the choice of dialysis modalities in any given country.

In 1999, we and others summarized the differences in health care structures, mainly focusing on industrial countries in Europe, and their impact on the selection of RRT modalities [35-37]. The countries were grouped into 'public' (Beveridge model), 'mixed' (Bismarck model) and 'private' (private insurance model) providers. In the Beveridge 'public' model, funding is based mainly on taxation and is characterized by a centrally organized $\mathrm{Na}$ tional Health Service where the services are provided by mainly public health providers (hospitals, community doctors). In this model, health care budgets compete with other spending priorities. The countries using this model are the UK, Italy, Spain, Sweden, Denmark, Norway, Finland, and Canada. The Bismarck 'mixed' model is mainly funded by a premium-financed social/mandatory insurance and is found in countries such as Germany, France, Austria, Switzerland, and the Benelux countries. Also Japan has a premium-based mandatory insurance funds system. This model results in a mix of private and public providers and allows more flexible spending on healthcare. In the 'private' insurance model, funding of the system is based on premiums, paid into private insurance companies, and in its pure form actually exists only in the US. In this system, the funding is predominantly private, with the exception of social care through the former Medicare and Medicaid. The great majority of the providers in this model belong to the private sector. However, the provider structure for ESRD therapy may be different from the general health care provider system. Figure 1 illustrates the ESRD provider systems for different countries.

In 1994, in 'public' provider countries, $20-52 \%$ of dialysis patients were treated with home therapies (HD and PD), and the number of patients with renal transplants was $45-81 \%$ of all ESRD patients. In 'mixed' provider countries, only $9-17 \%$ of all dialysis patients were treated with home therapies, and 20-48\% of ESRD patients had renal transplants. In 'private' provider countries, $17 \%$ US and $6 \%$ Japanese dialysis patients were treated with home therapies. Japan had $0.3 \%$ and the US $26 \%$ of ESRD pa- 

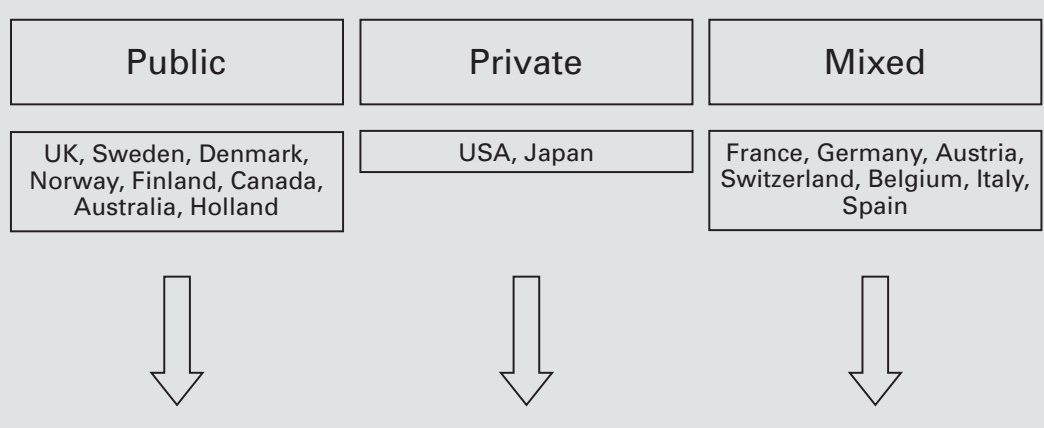

Fig. 1. The provider structure for ESRD therapies according to their health care model (by courtesy of Maria Wiedemann).
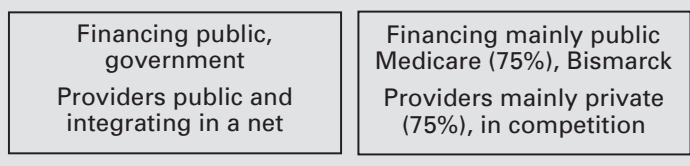

Social security/public Providers mixed, public and private in competition

Source: Basys 1995, Nera 1993, WHO 1996, own data

Table 1. Absolute incidence rates per million population at day 91 of established therapy, as reported in the annual DTA/ERA report

\begin{tabular}{|c|c|c|c|c|c|c|c|c|c|c|c|c|c|c|c|c|c|c|}
\hline & \multicolumn{3}{|l|}{1998} & \multicolumn{3}{|l|}{1999} & \multicolumn{3}{|l|}{2000} & \multicolumn{3}{|c|}{2001} & \multicolumn{3}{|l|}{2002} & \multicolumn{3}{|c|}{2003} \\
\hline Austria & 10.5 & 92.3 & 3 & 11.9 & 101.8 & 3.4 & 10.5 & 100.3 & 3 & 12.3 & 103.2 & 4.1 & 10 & 101.4 & 4.1 & 12.2 & 109.5 & 3.5 \\
\hline Belgium (French) & - & - & - & 14.2 & 121.3 & 8.6 & - & - & - & 13.7 & 137.6 & 1.6 & - & - & - & - & - & - \\
\hline Denmark & - & - & - & 34.6 & 71.6 & 0.4 & - & - & - & 42.8 & 81.2 & 3.5 & 36.3 & 80.9 & 3 & 39.3 & 80.2 & 4.5 \\
\hline Finland & - & - & - & 25.7 & 57.5 & 1.4 & - & - & - & 21 & 62.2 & 0.6 & 23.7 & 65.1 & 0.2 & 26 & 61.8 & 1.7 \\
\hline Norway & 14 & 57.3 & 12.2 & 13.2 & 58 & 10.5 & 16.9 & 62.2 & 10.5 & 11.5 & 63.2 & 11.1 & 18.3 & 56.4 & 11.9 & 16.6 & 60.9 & 11.2 \\
\hline Spain (Catalonia) & 12.4 & 113.4 & 2.1 & 10.3 & 130.2 & 3.1 & 9.8 & 117.5 & 2.2 & 13.5 & 124.6 & 1.3 & 9.4 & 125.7 & 3.4 & 8.8 & 124.5 & 4.6 \\
\hline Spain (Basque) & - & - & - & - & - & - & - & - & - & 38.2 & 74 & 1.0 & 25.1 & 67.1 & 1.4 & 30.4 & 93.6 & 0.5 \\
\hline Spain (Valencia) & - & - & - & - & - & - & - & - & - & - & - & - & 14.3 & 135.5 & 0.7 & 21.7 & 122.3 & 0.7 \\
\hline Sweden & - & - & - & 35.6 & 69.1 & 0 & - & - & - & 35 & 68.8 & 5.5 & 35.9 & 72.9 & 4.9 & 33.5 & 70 & 3.2 \\
\hline Netherlands & 29.9 & 51.8 & 2.4 & 30.4 & 52.9 & 3.6 & 31.2 & 56.2 & 4.7 & 30.4 & 52.9 & 3.6 & 26.2 & 62.4 & 4 & 25.1 & 61 & 4.4 \\
\hline UK, Scotland & - & - & - & 32 & 59.2 & 2.0 & - & - & - & 29 & 51.8 & 4.6 & 24.1 & 71.2 & 1.8 & 23.9 & 81.3 & 2.6 \\
\hline
\end{tabular}

DTA/ERA = Dialysis and Transplantation Association/ European Renal Association; Tx = transplantation.

tients who received renal transplants [36]. Therefore, it seemed that provider structures influenced access to and choice of ESRD treatment.

Table 1 summarizes the absolute incident rates per million population at day 91 of established therapy (PD, HD, transplantation) over the years 1998-2003, as reported in the annual Dialysis and Transplantation Association/European Renal Association registry reports.

As can be derived from this table, it appears that the highest prevalence of PD was present in the public provider countries; however, important shifts in the utilization of PD were observed in selected countries. Even in the same country, major differences in incident patients starting RRT with a given modality can be observed. For example in Spain, three neighboring regions have wide different utilization rates of PD and HD, with a high PD utilization in the Basque country and a rather low rate in Catalonia.

Figure 2 is based on data from different registries and it is remarkable to observe the sometimes marked percentual decline of PD (based on patients per million population) in some countries between 1994 and 2002, be it in the public provider system (Canada $-5 \%, \mathrm{UK}-21 \%$, Finland $-12 \%$ ), the mixed provider system (Switzerland 


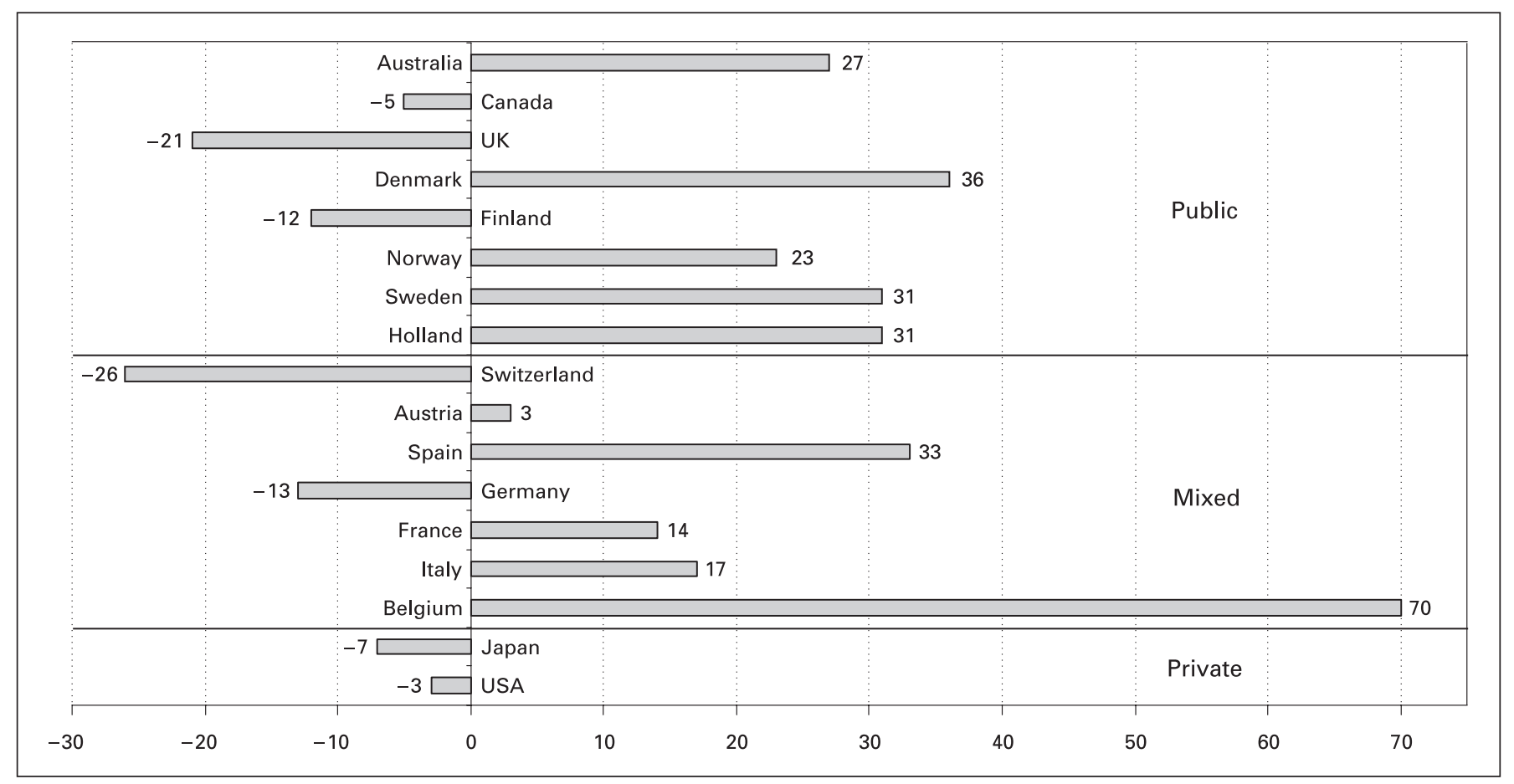

Fig. 2. Change in prevalence in PD. Growth and decrease in patients (in percentage) based on per million population from 1994 to 2002 (by courtesy of Maria Wiedemann).

$-26 \%$, Germany $-13 \%$ ), or in the private provider system (Japan $-7 \%$ and the USA -3\%).

On the other hand, in many countries, also in some mixed provider countries, the share of PD has increased, notably in Spain, France, Italy, and Belgium. Particularly in Belgium, the increase is quite dramatic (+70\%) and can be explained by a substantial increase in the reimbursement for all dialysis outside the hospital (home and/or so-called low care, autonomous dialysis centers). For many years there has been a moratorium on the number of hospital dialysis centers in Belgium, and until recently, the reimbursement for the hospital center HD was higher if a hospital center had a minimum proportion of the patients under its care in satellite HD or PD.

Hence, another reason for the rise in PD utilization is that a more incentive reimbursement has been introduced. Table 2 illustrates the changes in reimbursement for the three PD modalities in Belgium. Before 2001, the weekly reimbursement was not different whether the patient used CAPD or cycler PD, or was assisted by a home nursing service. From 2002 on, these reimbursements were adapted, and the difference in reimbursement between the home-assisted PD and the CAPD without assistance is paid to the nursing service. The reimburse-
Table 2. Reimbursement prices for several PD modalities in Belgium between 1996 and 2005

\begin{tabular}{llll}
\hline & $\begin{array}{l}\text { PD manual } \\
\text { EUR/week }\end{array}$ & $\begin{array}{l}\text { PD cycler } \\
\text { EUR/week }\end{array}$ & $\begin{array}{l}\text { PD with nurse } \\
\text { assistance EUR/week }\end{array}$ \\
\hline 1996 & 619.73 & idem & idem \\
2001 & 619.73 & idem & 793.26 (from 1/7) \\
2002 & 619.73 & 694.10 & 793.26 \\
2003 & $659.21($ from 1/7) & 733.58 & 832.74 (from 1/7) \\
2004 & 672.39 & 748.25 & 849.39 \\
2005 & 685.79 & 763.21 & 866.32 \\
\hline
\end{tabular}

ment sum covers all the costs for the fluids and all equipment needed. It should be emphasized that no separated honorarium for the nephrologist is foreseen.

By contrast, the decline in PD in the UK can easily be explained by a substantial increase in low-care satellite HD centers (from 842 in 1998 to 1,431 in 2002) and, to a lower extent, by an increase in hospital HD facilities (from 1,376 dialysis posts in 1998 to 1,621 in 2002) which of course has had a negative impact on the total PD patient population. It is of note that in the 1980s, UK pa- 
Table 3. Evolution of the number of dialysis patients in Switzerland according to the center structure

\begin{tabular}{lrrrrr}
\hline & 1998 & 1999 & 2000 & 2001 & 2002 \\
\hline HD public centers & 1,583 & 1,600 & 1,659 & 1,708 & 1,793 \\
HD private centers & 299 & 315 & 400 & 439 & 484 \\
PD public centers & 256 & 259 & 271 & 267 & 280 \\
PD private centers & 5 & 9 & 8 & 10 & 14 \\
\hline Total & 2,143 & 2,183 & 2,338 & 2,424 & 2,571 \\
\hline
\end{tabular}

tients were more or less 'forced' into PD because the more expensive center HD modality was rarely available.

In 2002/2003, approximately 57,000 patients were enrolled in chronic dialysis programs in Germany; less than $5 \%$ were on PD [38]. In contrast, in the early 1990 s, almost $10 \%$ of the ESRD patients were treated with PD. The reasons for this decline are numerous, but one of the main explanations is the high number of HD facilities with even underutilized capacities in many small cities, making home dialysis, be it PD or home HD, virtually superfluous. In addition, before 2002, unbalanced renumeration for PD was an additional negative factor [38]. Since 2002, a new payment contract has been introduced in Germany which is more favorable for PD; one would thus expect a rapid increase in the PD population, but this could not be observed during the past 2 years. The reasons for this so far neutral impact on PD utilization are probably the still high number of HD units available, the unfamiliarity of the German nephrologists with PD, and lack of training of young fellows in PD in academic institutions.

In Switzerland, the reimbursement rates foreseen for center HD do allow centers some financial benefit depending on the center type, organization, and social security regulations [39]. The same does not apply to PD, since no reimbursement is foreseen for the supervision made by the center staff when dialysis is practiced at home. This means that home therapy has until now been a rather idealistic therapy applied by idealistic nephrologists. In addition, Switzerland, a mixed provider country, is a nice illustration of the impact of the provider structure on the distribution of PD utilization. Table 3 is taken from Wauters and Uehlinger [39], and despite the fact that among the 70 Swiss dialysis units, 32 practice PD (46\%), when subdivided according to their structure, only 2 out of 19 private units (11\%) practice PD in contrast with 30 out of 51 public units (59\%).
In France, where the prevalence of ESRD is among the highest in the world, the mode of dialysis in 2003 was center HD in $60.8 \%$ of patients and out-center HD in $30.0 \%$, mainly in the form of self-care HD. PD was only applied in 6-10\%, mostly in the CAPD modality [40].

In central and eastern European countries, dramatic changes in the availability of renal replacement therapy have occurred after their political and economic independence from the former Soviet Union. Some of these countries have joined the EU, and in the future, it is hoped that their registries will become part of the comprehensive European Dialysis and Transplantation Association/ European Renal Association registry. According to a report published in 2000 [41], the overall utilization of PD was $10.3 \%$, ranging from $1 \%$ in Macedonia to as high as 49\% in Estonia. PD was well developed in Estonia and Latvia and was growing in Poland and Romania; on the other hand, between 1995 and 1998, it decreased in Hungary and Slovakia, possibly reflecting the impact of growing privatization of the dialysis sector in these countries [41].

An example of a wide difference in PD utilization are the Baltic states; in 1999, Lithuania rarely applied PD (4\% of all patients), while neighboring countries like Estonia and Latvia applied it much more frequently [42].

An illustration of the impact of privatization of the RRT sector on the utilization of PD is Slovenia [43]. From 1990 to 2003, the fraction of private HD patients increased from 13.1 to $21 \%$; between 2000 and 2002, a decline in PD was observed, ranging between 12 and 3\%. In 2003, however, an increase in PD was noted with approximately $6 \%$.

An interesting analysis of the relation between reimbursement policies and utilization of a given dialysis modality was recently published in Bulgaria [44]. The distribution of the payments of the expenditures for dialysis is such that the Ministry of Health covers over $60 \%$ of the costs of CAPD, compared with 33\% of those of HD. Despite CAPD being less expensive overall, the major financing body (the Ministry) perceives CAPD as twice as expensive as HD, so that at least from the point of view of the public health administration, there is little financial incentive to encourage PD. Despite this, PD as treatment modality has increased from $0.64 \%$ in 1993 to $7.1 \%$ in 2003 [44].

A spectacular increase in PD utilization has been observed in Romania from 20 per million population in 1995 to 952 per million population in 2003 [45]. According to the Romanian colleagues, this 'success story' is on the one hand explained by the poor infrastructure and 
still long travel distances from home to dialysis centers, by the adoption of the 'integrated care' approach, and on the other hand, by a rather low developed renal transplantation program in Romania [45].

The concept of an integrated care approach to ESRD advocates that HD, PD, and renal transplantation should all be offered to the patient in an unbiased way, and that all three modalities may be a part of treatment during the patient's lifetime. For many, PD will be a reasonable initial choice, hopefully followed by renal transplantation, but otherwise with timely conversion to HD should complications arise from PD [46, 47].

In the years after its first description, the soundness of this concept, which was based on the experience of a single center, has been confirmed by data of larger data bases [11] and in a small prospective study [48].

The cost reduction when starting a 'PD first' therapy compared with immediately starting HD has recently been calculated based on Medicare expenditures [49]. The unadjusted average annual Medicare expenditure (in 2004) for PD as first modality was USD 53,277, and USD 72,189 for HD. Compared with the 'HD, no switch' subgroup, 'PD, no switch' had a significantly lower annual expenditure (USD 44,111 vs. 72,185 ). 'PD with at least one switch' and 'HD with at least one switch' had a lower or similar annual expenditure of USD 66,639 versus 72,335 , respectively. After adjusting for patient characteristics, annual Medicare expenditure was still significantly lower for patients with PD as the initial modality (USD 56,807 vs. 68,253). Similarly, compared with the 'HD, no switch' subgroup, 'PD, no switch' and 'PD with at least one switch' had a significantly lower total expenditure. Further analysis showed that time to first switch also independently impacted total expenditure.

In conclusion, the utilization of PD in Europe varies very widely. In some countries, the prevalence of PD has risen during the last years, in others, as in other non-European countries, a decline in its utilization is observed; the reasons for this variability are numerous, and this review has attempted to define a number of medical and non-medical factors involved in this evolution.

We believe that, among other factors, financial and reimbursement issues play an important role in the selection of the first modality of RRT and its application sequence. If the trend for declining utilization of $\mathrm{PD}$ in Europe should be reversed, a number of important steps should be implemented. Firstly, early referral of patients with chronic kidney disease is essential for their timely information about the therapeutic options. This information should not be exclusively provided by the nephrologist, but should be incorporated in a chronic kidney disease integrated care team approach. Secondly, at least in some countries, a firm commitment of nephrologists to PD should be aimed at by providing the trainee in nephrology adequate training in this modality. Thirdly, financial incentives should be provided for the caregivers, at least in some countries, for promoting PD, particularly since in many European countries, HD is financially still more attractive. These measures require combined efforts from all partners involved in the care of patients with ESRD, public and/or private insurances, the dialysis industry, and the renal community at large.

\section{References}

1 Oreopoulos DG, Robson M, Faller B, Ogilvie R, Rapoport A, deVeber GA: Continuous ambulatory peritoneal dialysis: a new era in the treatment of chronic renal failure. Clin Nephrol 1979;11:125-128.

2 Prichard S: Will peritoneal dialysis be left behind? Semin Dial 2005;18:167-170.

-3 Friedman EA: Critical appraisal of continuous ambulatory peritoneal dialysis. Annu Rev Med 1984;35:233-248.

-4 ShaldonS, KochKM, QuellhorstE,Lonnemann G, Dinarello CA: CAPD is a second-class treatment. Contrib Nephrol 1985;44:163-172.

-5 Bloembergen WE, Port FK, Mauger EA, Wolfe RA: A comparison of mortality between patients treated with hemodialysis and peritoneal dialysis. J Am Soc Nephrol 1995;6:177183.
6 Held PJ, Port FK, Turenne MN, Gaylin DS, Hamburger RJ, Wolfe RA: Continuous ambulatory peritoneal dialysis and hemodialysis: comparison of patient mortality with adjustment for comorbid conditions. Kidney Int 1994:45:1163-1169.

7 Li PK, Law MC, Chow KM, Chan WK, Szeto CC, Cheng YL, Wong TY, Leung CB, Wang AY, Lui SF, Yu AW: Comparison of clinical outcome and ease of handling in two doublebag systems in continuous ambulatory peritoneal dialysis: a prospective, randomized, controlled, multicenter study. Am J Kidney Dis 2002;40:373-380. $\checkmark 8$ Lee HY, Park HC, Seo BJ, Do JY, Yun SR, Song HY, Kim YH, Kim YL, Kim DJ, Kim YS, Ahn C, Kim MJ, Shin SK: Superior patient survival for continuous ambulatory peritoneal dialysis patients treated with a peritoneal dialysis fluid with neutral $\mathrm{pH}$ and low glucose degradation product concentration (balance). Perit Dial Int 2005;25:248-255.

$\checkmark$ Collins AJ, Hao W, Xia H, Ebben JP, Everson SE, Constantini EG, Ma JZ: Mortality risks of peritoneal dialysis and hemodialysis. Am J Kidney Dis 1999;34:1065-1074.

10 Fenton SS, Schaubel DE, Desmeules M, Morrison HI, Mao Y, Copleston P, Jeffery JR, Kjellstrand CM: Hemodialysis versus peritoneal dialysis: a comparison of adjusted mortality rates. Am J Kidney Dis 1997;30:334-342. 
-11 Heaf JG, Lokkegaard H, Madsen M: Initial survival advantage of peritoneal dialysis relative to haemodialysis. Nephrol Dial Transplant 2002; 17:112-117.

-12 Termorshuizen F, Korevaar JC, Dekker FW, van Manen JG, Boeschoten EW, Krediet RT: Hemodialysis and peritoneal dialysis: comparison of adjusted mortality rates according to the duration of dialysis: analysis of The Netherlands Cooperative Study on the Adequacy of Dialysis 2. J Am Soc Nephrol 2003;14:28512860.

13 Vonesh EF, Snyder JJ, Foley RN, Collins AJ: The differential impact of risk factors on mortality in hemodialysis and peritoneal dialysis. Kidney Int 2004;66:2389-2401.

-14 Jaar BG, Coresh J, Plantinga LC, Fink NE, Klag MJ, Levey AS, Levin NW, Sadler JH, Kliger A, Powe NR: Comparing the risk for death with peritoneal dialysis and hemodialysis in a national cohort of patients with chronic kidney disease. Ann Intern Med 2005;143: 174-183.

-15 Van Biesen W, Vanholder R, Veys N, Lameire $\mathrm{N}$ : Peritoneal dialysis in anuric patients: concerns and cautions. Semin Dial 2002;15:305310 .

16 Churchill DN, Taylor DW, Keshaviah PR, the Canada-USA Peritoneal Dialysis Study Group: Adequacy of dialysis and nutrition in chronic peritoneal dialysis: association with clinical outcomes. J Am Soc Nephrol 1996;7:198-207.

17 Bargman JM, Thorpe KE, Churchill DN: Relative contribution of residual renal function and peritoneal clearance to adequacy of dialysis: a reanalysis of the CANUSA study. J Am Soc Nephrol 2001;12:2158-2162.

- 18 Szeto CC, Wong TY, Chow KM, Leung CB, Law MC, Wang AY, Lui SF, Li PK: Impact of dialysis adequacy on the mortality and morbidity of anuric Chinese patients receiving continuous ambulatory peritoneal dialysis. J Am Soc Nephrol 2001;12:355-360.

-19 Paniagua R, Amato D, Vonesh E, Correa-Rotter R, Ramos A, Moran J, Mujais S: Effects of increased peritoneal clearances on mortality rates in peritoneal dialysis: ADEMEX, a prospective, randomized, controlled trial. J Am Soc Nephrol 2002;13:1307-1320.

20 Burkart JM: The ADEMEX study and its implications for peritoneal dialysis adequacy. Semin Dial 2003;16:1-4.

21 Cueto-Manzano AM, Correa-Rotter R: Is high peritoneal transport rate an independent risk factor for CAPD mortality? Kidney Int 2000; 57:314-320.

22 Davies SJ, Phillips L, Russell GI: Peritoneal solute transport predicts survival on CAPD independently of residual renal function. Nephrol Dial Transplant 1998;13:962-968.

23 Churchill DN, Thorpe KE, Nolph KD, Keshaviah PR, Oreopoulos DG, Page D: Increased peritoneal membrane transport is associated with decreased patient and technique survival for continuous peritoneal dialysis patients. The Canada-USA (CANUSA) Peritoneal Dialysis Study Group. J Am Soc Nephrol 1998;9:12851292.
24 Brown EA, Davies SJ, Rutherford P, Meeus F, Borras M, Riegel W, Divino Filho JC, Vonesh E, van Bree M: Survival of functionally anuric patients on automated peritoneal dialysis: the European APD Outcome Study. J Am Soc Nephrol 2003;14:2948-2957.

25 Rodriguez-Carmona A, Fontan MP: Sodium removal in patients undergoing CAPD and automated peritoneal dialysis. Perit Dial Int 2002;22:705-713.

26 Davies SJ, Woodrow G, Donovan K, Plum J, Williams P, Johansson AC, Bosselmann HP, Heimburger O, Simonsen O, Davenport A, Tranaeus A, Divino Filho JC: Icodextrin improves the fluid status of peritoneal dialysis patients: results of a double-blind randomized controlled trial. J Am Soc Nephrol 2003;14: 2338-2344.

27 Nissenson AR, Prichard SS, Cheng IK, Gokal R, Kubota M, Maiorca R, Riella MC, Rottembourg J, Stewart JH: Non-medical factors that impact on ESRD modality selection. Kidney Int Suppl 1993;40:S120-S127.

28 Nissenson AR, Prichard SS, Cheng IK, Gokal R, Kubota M, Maiorca R, Riella MC, Rottembourg J, Stewart JH: ESRD modality selection into the 21st century: the importance of nonmedical factors. ASAIO J 1997;43:143-150.

29 Mehrotra R, Blake P, Berman N, Nolph KD: An analysis of dialysis training in the United States and Canada. Am J Kidney Dis 2002;40: 152-160.

30 Lameire N, Van Biesen W, Dombros N, Dratwa M, Faller B, Gahl GM, Gokal R, Krediet RT, La Greca G, Maiorca R, Matthys E, Ryckelynck JP, Selgas R, Walls J: The referral pattern of patients with ESRD is a determinant in the choice of dialysis modality. Perit Dial Int 1997; 17(suppl 2):S161-S166.

-31 Mendelssohn DC, Mullaney SR, Jung B, Blake PG, Mehta RL: What do American nephrologists think about dialysis modality selection? Am J Kidney Dis 2001;37:22-29.

32 Rubin HR, Fink NE, Plantinga LC, Sadler JH, Kliger AS, Powe NR: Patient ratings of dialysis care with peritoneal dialysis vs hemodialysis. JAMA 2004;291:697-703.

- 33 Mehrotra R, Marsh D, Vonesh E, Peters V, Nissenson A: Patient education and access of ESRD patients to renal replacement therapies beyond in-center hemodialysis. Kidney Int 2005;68:378-390.

34 Goovaerts T, Jadoul M, Goffin E: Influence of a pre-dialysis education programme (PDEP) on the mode of renal replacement therapy. Nephrol Dial Transplant 2005;20:18421847.

35 De Vecchi AF, Dratwa M, Wiedemann ME: Healthcare systems and end-stage renal disease (ESRD) therapies - An international review: costs and reimbursement/funding of ESRD therapies. Nephrol Dial Transplant 1999; 14(suppl 6):31-41.
36 Horl WH, de Alvaro F, Williams PF: Healthcare systems and end-stage renal disease (ESRD) therapies - An international review: access to ESRD treatments. Nephrol Dial Transplant 1999;14(suppl 6):10-15.

-37 Lameire N, Joffe P, Wiedemann M: Healthcare systems - An international review: an overview. Nephrol Dial Transplant 1999; 14(suppl 6):3-9.

-38 Mettang T: Changes in dialysis reimbursement regulations in Germany. Perit Dial Int 2004; 24:526-527.

- 39 Wauters JP, Uehlinger D: Non-medical factors influencing peritoneal dialysis utilization: the Swiss experience. Nephrol Dial Transplant 2004; 19:1363-1367.

40 Macron-Nogues F, Vernay M, Ekong E, Thiard B, Salanave B, Fender P, Allemand H: The prevalence of ESRD treated with renal dialysis in France in 2003. Am J Kidney Dis 2005;46: 309-315.

41 Rutkowski B: Changing pattern of end-stage renal disease in central and eastern Europe. Nephrol Dial Transplant 2000;15:156-160.

42 Locatelli F, D’Amico M, Cernevskis H, Dainys B, Miglinas M, Luman M, Ots M, Ritz E: The epidemiology of end-stage renal disease in the Baltic countries: an evolving picture. Nephrol Dial Transplant 2001;16:1338-1342.

43 Buturovic-Ponikvar J: Renal replacement therapy in Slovenia: 2003 annual report. Ther Apher Dial 2005;9:196-201.

44 Vazelov ES, Krivoshiev SG, Antonov SA, Lazarov G: End-stage renal disease and peritoneal dialysis in Bulgaria. Perit Dial Int 2004;24: 512-517.

45 Mircescu G, Capsa D, Covic M, Caprioara MG, Gluhovschi G, Golea O, Ursea N, Garneata L, Cepoi V, Constantinovici N, Covic A: Nephrology and renal replacement therapy in Romania - Transition still continues (Cinderella story revisited). Nephrol Dial Transplant 2004; 19:2971-2980

46 Van Biesen W, Vanholder RC, Veys N, Dhondt A, Lameire NH: An evaluation of an integrative care approach for end-stage renal disease patients. J Am Soc Nephrol 2000;11:116125.

47 Davies SJ, Van Biesen W, Nicholas J, Lameire N: Integrated care. Perit Dial Int 2001;21(suppl 3):S269-S274

48 Korevaar JC, Feith GW, Dekker FW, van Manen JG, Boeschoten EW, Bossuyt PM, Krediet RT: Effect of starting with hemodialysis compared with peritoneal dialysis in patients new on dialysis treatment: a randomized controlled trial. Kidney Int 2003;64:22222228.

49 Shih YC, Guo A, Just PM, Mujais S: Impact of initial dialysis modality and modality switches on Medicare expenditures of end-stage renal disease patients. Kidney Int 2005;68:319329. 